\title{
EFFECT OF MELATONIN ON BUFFALO BULL SPERM FREEZABILITY, ULTRASTRUCTURE CHANGES AND FERTILIZING POTENTIALS
}

\author{
MOHAMED EL-RAEY*; BADR, M.R. ${ }^{* *}$; ASSI, M. M*** and RAWASH, Z.M.** \\ "Department of Theriogenology, Faculty of Veterinary Medicine, Benha University (http://www.fvtm.bu.edu.eg), P.O. \\ 13736, Tokh, Kaliobia, Egypt. \\ ***Artificial Insemination and Embryo Transfer Department, Animal Reproduction Research Institute, Al Haram, P.O. 12556, \\ Giza, Egypt.
}

Email: magdybadr69@yahoo.com

\section{ABSTRACT}

Received at: 10/12/2014

Accepted: 7/2/2015
Cryopreservation induces sublethal damage to the spermatozoa, which leads to reduce their fertile life. The objective of the present study was to investigate the effect of melatonin on freezability, ultrastructure and fertilizing potentials of the buffalo spermatozoa. Buffalo spermatozoa were cryopresreved with Tris egg yolk extender containing $7 \%$ glycerol supplemented with $(0.100,0.250,0.500,0.750$ and $1 \mathrm{mM}$ melatonin) or Tris-based extender only (control). Cryopresreved spermatozoa were assessed for post-thawing sperm motility, viability and acrosomal integrity, ultrastructure changes and fertilizing potentials. The current results clearly indicated that adding $0.1 \mathrm{mM}$ melatonin to Tris extender significantly improved $(\mathrm{P}<0.05)$ postthawing sperm motility and viability index following cryopreservation $(60.00 \pm 2.9 \%$ and $157.5 \pm 11.8$, respectively) compared with the control spermatozoa $(45.00 \pm 2.90 \%$ and 97.00 \pm 9.09 , respectively). The current results illustrated that addition of $0.1 \mathrm{mM}$ melatonin protected the plasma membrane, acrosomal region and mitochondria and maintained the ultrastructure integrity of the cryopresreved spermatozoa compared with the control spermatozoa. The present data indicated that addition of melatonin at a dose of 0.1 and $0.25 \mathrm{mM}$ to the semen extender significant increased $(\mathrm{P}<0.05)$ the positive HOST percent (83.66 and $81.33 \%$, respectively) compared with the control semen $(43.33 \%)$. Additionally, the current results revealed that addition of $0.1 \mathrm{mM}$ and $0.25 \mathrm{mM}$ melatonin to the semen extender highly significant increased $(\mathrm{P}<0.01)$ the pregnancy rate $(66.67$ and $60.43 \%$, respectively) compared with the control semen $(45.65 \%)$. Therefore, the present results revealed that addition of melatonin to the freezing extender might improve semen quality and reduce cryodamage of the buffalo bull spermatozoa.

Key words: Melatonin, semen extender, cryopreservation, HOST, ultrastructure and conception rate.

\section{INTRODUCTION}

Semen cryopreservation offers many advantages to the livestock industry, particularly in conjunction with allowing the widespread dissemination of valuable genetic material by means of artificial insemination (Bucak et al., 2009). The success of an AI program depends on the proper management of semen collection, storage and use (Leboeuf et al., 2000). Although, many protocols have been developed for semen cryopreservation, sperm cryosurvival rate is still not optimum in the buffalo. Cryopreservation induces some irreversible damages in sperm cells (Medeiros et al., 2002). Factors responsible for these damages includes; changes in temperature, ice formation, access of reactive oxygen species and lipid peroxidation, alterations in sperm membrane, toxicity of cryoprotectants and osmotic stress which reduces the post thaw quality of semen (Watson, 2000). To keep the cell alive during cryopreservation process, plasma membrane is a key component that must be maintained (Aboagla and Terada, 2003). The plasma membrane of mammalian spermatozoa contains high concentrations of polyunsaturated fatty acids, which make it susceptible to reactive oxygen species (ROS) induced peroxidative damage with a subsequent loss of sperm functions (Lenzi et al., 2002). There are several substances used to protect sperm plasma membrane during cryopreservation, one of the most important of 
them melatonin. Melatonin (N-acetyl-5Methoxytryptamine) an indole derivative secreted rhythmically from the pineal gland and played a major role in regulating the circadian clock in mammals in general and regulating the reproductive functions in particular (Reiter, 1991). The role of melatonin in modulating the reproduction is still obscure (Berlinguer et al., 2009). More recent studies had demonstrated that, melatonin had an antioxidant and powerful direct scavenger effect that protected the cells from the free radicals (Adriaens et al., 2006 and Kang et al., 2009). Melatonin and its metabolites potently scavenge ROS (Reiter et al., 2005), thus altering redox-sensitive events and preventing oxidative damage and improve sperm motility during sperm liquid storage or in the unfrozen state (Ashrafi et al., 2001 and Kang et al., 2009). Additionally, melatonin might be involved in the protection of different cell types against damage-induced apoptosis (Baydas et al., 2005, Casao et al., 2010 and Espino et al., 2011). Moreover, melatonin exerts several beneficial actions on sperm fertilizing ability such as induction of capacitation (Bornman et al., 1989) and hyperactivation (Fujinoki 2008). However, the effect of melatonin on the integrity and fine plasma membrane structure of buffalo spermatozoa was rarely evaluated. So the current study aimed to estimate the influence of melatonin on the fine ultrastructure changes and the fertilizing potentials of buffalo spermatozoa.

\section{MATERIALS and METHODS}

\section{Diluent Preparation}

The cryoprotective extender used in the current study was composed of $2.42 \mathrm{~g}$ Tris, $1.48 \mathrm{~g}$ citric acid, 1.00 $\mathrm{g}$ fructose, $6.6 \mathrm{ml}$ glycerol, $20 \mathrm{ml}$ egg yolk, $25 \mathrm{mg}$ gentamicin, and 50,000 IU penicillin; all of these components were dissolved in $100 \mathrm{ml}$ deionized water and supplemented with different concentrations of melatonin.

\section{Semen Collection}

Semen samples were obtained randomly from six fertile Egyptian buffalo bulls (aged 3 to 5 y) kept at the Animal Reproduction Research Institute farm (Cairo, Egypt). Two consecutive ejaculates were collected from each bull weekly for successive six weeks using an artificial vagina. The ejaculates were pooled to eliminate variability between the evaluated samples. The semen samples were assessed for volume, sperm concentration, and percentage of motile spermatozoa. The ejaculates with at least $70 \%$ motility, $800 \times 10^{6}$ sperm cells $/ \mathrm{ml}$ and $>85 \%$ normal sperm morphology were used for the present study. All experiments were done with at least 3 replicates for each group.

\section{Semen Processing}

After the evaluation of semen quality, the fresh semen samples were pooled and then split into 6 equal portions and diluted at $30^{\circ} \mathrm{C}$ with Tris-based extender supplemented with different concentrations of melatonin $(0.1,0.25,0.5,0.75$ and $1 \mathrm{mM})$ vs. Trisbased extender only (control) to obtain $120 \times 10^{6}$ sperm $/ \mathrm{ml}$. Melatonin (M5250-250mg, lot No. 068k1538; Sigma-Aldrich, St. Louis, MO) stock solution was prepared by dissolving powder in the diluent media according to its dissolving capability in solutions.

The required concentrations were achieved using serial dilution manner; depending on published papers (Succu et al., 2011). The current work used a broad range of melatonin concentrations to determine the ideal dose that should be used for buffalo semen extension. The fresh semen samples were transferred to pre warmed tubes. Semen was cooled from 37 to $5^{\circ} \mathrm{C}$ throughout $60 \mathrm{~min}$ in a cold cabinet. The cooled semen was loaded into $0.25 \mathrm{ml}$ polyvinyl chloride straws (IMV, L'Aigle, France), horizontally placed in a refrigerator and kept at $4{ }^{\circ} \mathrm{C}$ for $1 \mathrm{~h}$. These straws were then placed $6 \mathrm{~cm}$ above the liquid nitrogen surface where the temperature was approximately $-120^{\circ}$ C. After $15 \mathrm{~min}$, they were immersed directly into liquid nitrogen $\left(-196^{\circ} \mathrm{C}\right)$ for storage.

The straws were stored at least for 24 hour before evaluation. Frozen semen straws were thawed in water bath at $37^{\circ} \mathrm{C}$ for $30 \mathrm{sec}$. Post-thawing sperm motility; viability and acrosomal integrity were assessed according to Mohammed et al. (1998).

\section{Hypo-osmotic swelling test}

Hypo-Osmotic Swelling Test (HOST) of spermatozoa, as an in-vitro fertility test, was conducted to evaluate the semen sample in the procedure as described by Revell and Morde (1994). Proportion of sperm cells exhibiting hypo-osmotic swollen positive response was expressed as percent (Correa and Zavos, 1994).

\section{Ultrastructure analysis of the cryopresreved spermatozoa}

The ultrastructure changes occurred for the cryopresreved buffalo spermatozoa were evaluated by transmission electron microscopy (TEM). Straws from each treatment were washed three times by centrifugation at $1000 \mathrm{rpm}$ for $5 \mathrm{~min}$ using PBS (Phosphate Buffered Saline). The frozen-thawed semen was prefixed for $2-3 \mathrm{~h}$ with PBS containing $2 \%$ glutaraldehyde, washed three times by centrifugation at $1000 \mathrm{rpm}$ with $\mathrm{PBS}(\mathrm{pH}$ 7.4) for 5 min at $4^{\circ} \mathrm{C}$ and post-fixed in $1 \%$ osmium tetroxide for 1-2 $\mathrm{h}$ at $4^{\circ} \mathrm{C}$ (Boonkusol, 2010). Spermatozoa were dehydrated in propylene oxide and embedded in epon resin. Ultrathin sections were cut using the Leica EM UC6 ultramicrotome and stained with uranylacetate 
and lead citrate. Randomly fields were examined by a transmission electronic microscope (JEOL-EM-100 S at $80 \mathrm{Kv}$ at VACSERA- Electron Microscopy Unit) and photographed for further analysis.

\section{Evaluation of fertilizing potentials of the semen}

A preliminary fertility trial was performed to compare between control semen and melatonin treated semen. Buffalo cows were randomly assigned to one of six treated groups: group $1 \quad(92$ buffaloes $)$ was inseminated using control semen; group 2 (93 buffaloes) was inseminated using $0.1 \mathrm{mM}$ melatonin treated semen, group 3 (91 buffaloes) was inseminated using $0.25 \mathrm{mM}$ melatonin treated semen, group 4 (87 buffaloes) was inseminated using 0.5 melatonin treated semen, group 5 (86 buffaloes) was inseminated using $0.75 \mathrm{mM}$ melatonin treated semen and group 6 (87 buffaloes) was inseminated using 1 $\mathrm{mM}$ melatonin treated semen. Pregnancy diagnosis was performed 45 days post-insemination by transrectal palpation.

\section{Statistical analysis}

All data were analyzed by using Costat Computer Program (1986), Version 3.03 copyright Cottort
Software, and were compared by the least significant difference least (LSD) at 5\% levels of probability. The results were expressed as means \pm SE. The mean values of the percentages of motile sperm, acrosomeintact sperm, enzyme activity and embryo development were compared using Duncan's multiple range test by one-way ANOVA procedure, when the F-value was significant $(\mathrm{P}<0.05)$. Sperm fertilizing capacity and zygotes developmental competences were assessed using Chi-square at $(\mathrm{P}<0.01$ and 0.05 , respectively).

\section{RESULTS}

As shown in Fig (1), The current results clearly indicated that adding 0.1 and $0.25 \mathrm{mM}$ of melatonin to Tris extender significantly improved $(\mathrm{P}<0.05)$ postthawing sperm motility $(60.00 \pm 2.9$ and $55.00 \pm 5.01$, respectively), viability index (157.5 \pm 11.8 and $150.83 \pm 8.21$, respectively) compared with the control spermatozoa $(45.00 \pm 2.905 \%$ and $97.00 \pm 9.09$, respectively).

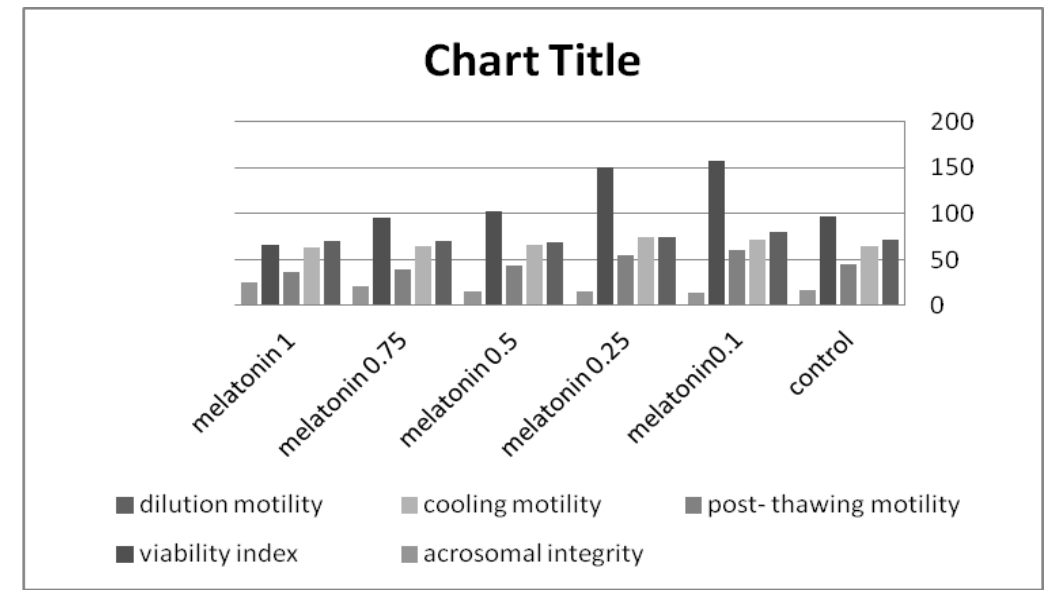

Fig. 1: Effect of melatonin supplementation to buffalo semen extender on the frozen-thawed spermatozoa characteristics.

Electron microscopic images of sagital sections of the frozen thawed buffalo sperm cells in the control group showed, swollen plasma membrane segmentation of the outer acrosomal membrane and swollen acrosome (fig, 2 and 3). Mean while, the frozen thawed buffalo semen treated with $0.25 \mathrm{mM}$ melatonin illustrated a well defined and intact plasma membrane and intact outer and inner acrosomal membranes (fig, 4 and 5). Moreover, the control semen showed severe degeneration marked vacuolation in the mitochondria with complete absence of the transverse cristae (fig, 6). While, semen treated with $0.25 \mathrm{mM}$ melatonin illustrated homogenous mitochondria content and high-quality mitochondrial dense electron spaces with appeared transverse cristae (fig, 7 and 8).

\section{Hypo-Osmotic Swelling Test (HOST):}

Data regarding the hypo-osmotic swelling test are illustrated in fig. 9. A significant difference $(\mathrm{P}<0.05)$ was found to exist between the melatonin treated semen at a concentration of 0.1 and $0.25 \mathrm{mM}(83.66$ and $81.33 \%$, respectively) compared with the control group $(43.33 \%)$. 


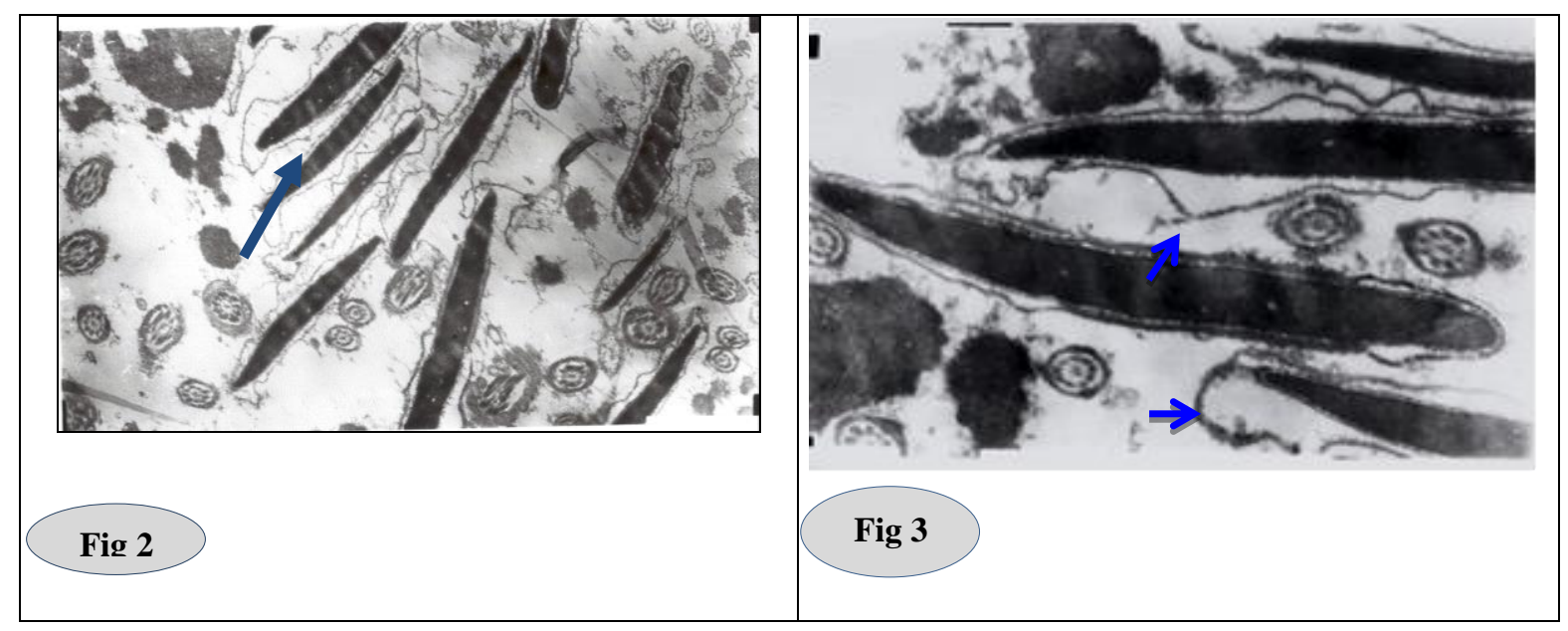

Fig. 2 \& 3: Electron micrograph for a sagital section in the sperm head from a frozen-thawed semen sample of control group illustrating swollen, degenerated and vacuolated plasma membrane, segmentation of the outer acrosomal membrane (OAM) and swollen acrosome (X 14000).

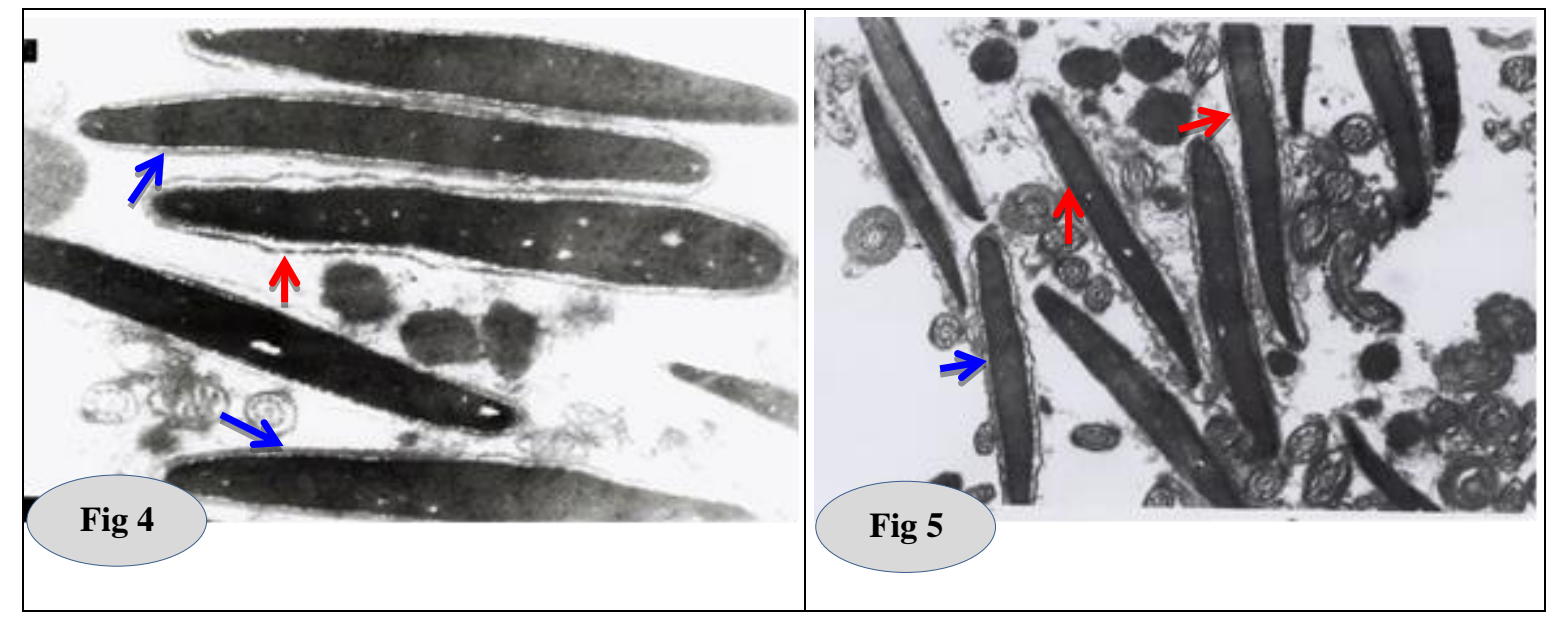

Fig. 4\&5: Electron micrograph for a sagital section in the sperm head from frozen-thawed semen sample treated with $0.1 \mathrm{mM}$ melatonin illustrating intact plasma membrane (PM) and the nucleus content $(\mathrm{N})$ is homogenous in the electron density. Also, outer and inner acrosomal membranes are intact and the subacrosomal space is evident ( $\times$ 2000). Also electron micrograph for a sagittal section in the sperm from a frozen-thawed semen sample illustrating intact outer acrosomal membrane (OAM) inner acrosomal membrane (IAM) in the electron density $(\times 10000)$.

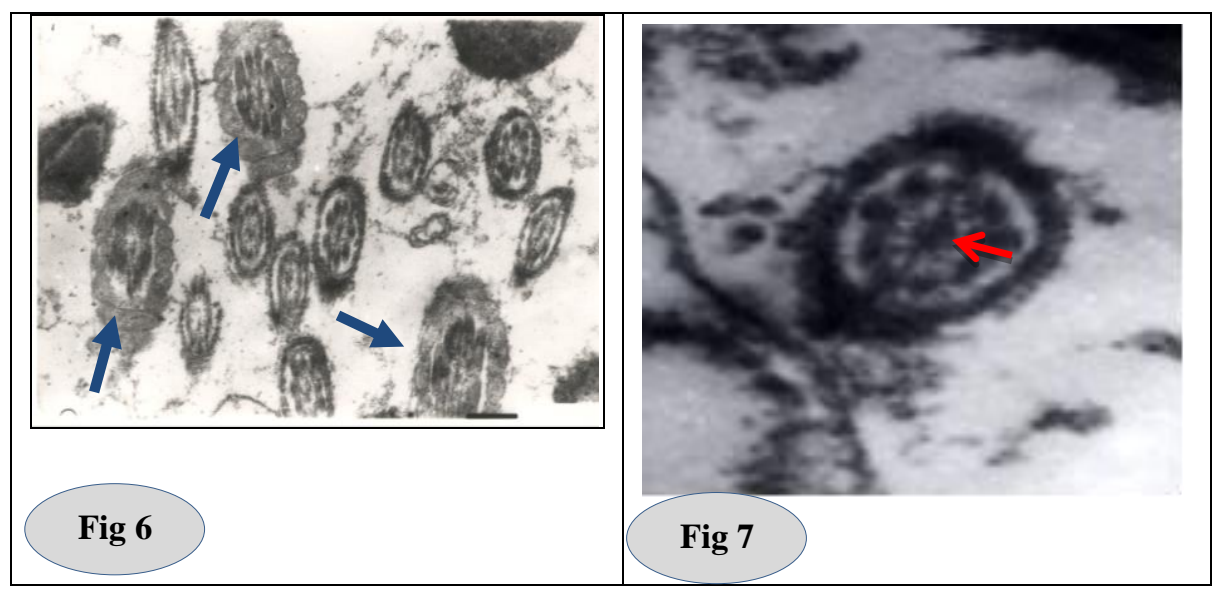




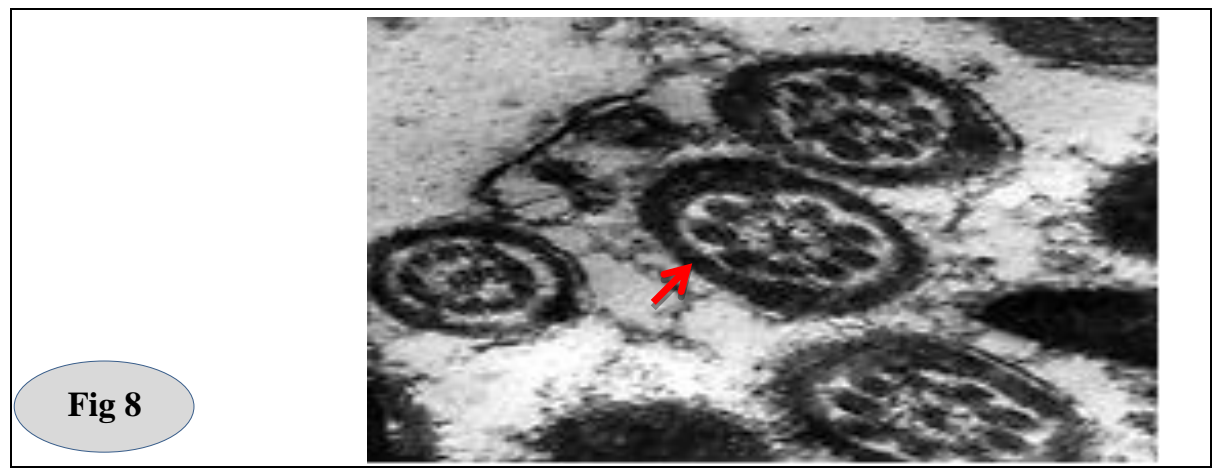

Fig. 6: Electron micrograph of a cross section in the neck region (note the presence of mitochondria in different orientation) of sperm from a frozen-thawed semen sample of control group showing severe degeneration (marked vacuolation) in the mitochondria that contained electron-translucent spaces with complete absence of the transverse cristae and some mitochondria are completely disappeared $(\times 20000)$.

Fig: 7\&8: Electron micrograph of a cross section in the mid-piece region and the tail from a frozen-thawed semen sample treated with $0.1 \mathrm{mM}$ melatonin illustrating good mitochondrial dense electron spaces with appeared transverse cristae $(\times 25000)$

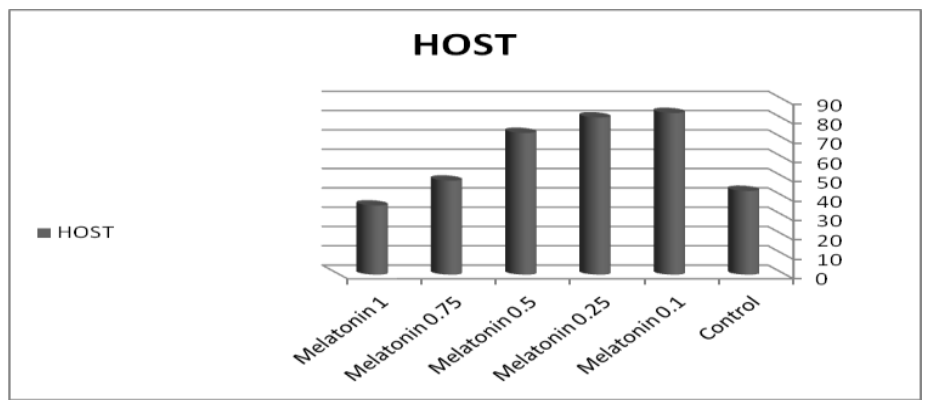

Fig. 9: Effect of melatonin addition to the freezing extender on the HOST\%.

Data regarding the effect of fortification of semen extender with different melatonin concentrations on the pregnancy rate is demonstrated in Fig. 10. The results showed that addition of $0.1 \mathrm{mM}$ and $0.25 \mathrm{mM}$ melatonin to the semen extender highly significant $(\mathrm{P}<0.01)$ augmented the pregnancy rate $(66.67$ and $60.43 \%$, respectively) compared with the control semen $(45.65 \%)$. Moreover, addition of high concentration $(1 \mathrm{mM})$ of melatonin to the semen extender drastically reduced the pregnancy rate $(28.74 \%)$.

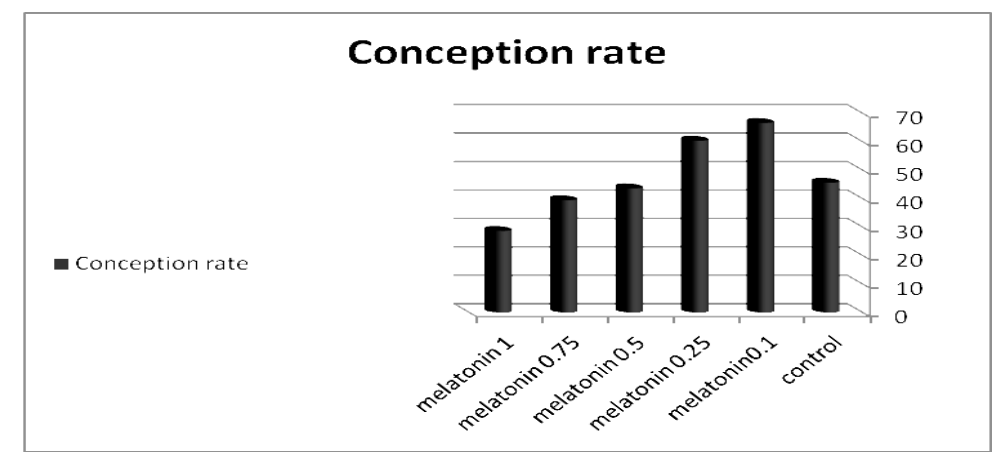

Fig. 10: Effect of melatonin addition to the freezing extender on the conception rate.

\section{DISCUSSION}

The current results revealed that melatonin supplementation to Tris extender prior to cryopreservation resulted in fantastic and protecting functions on the post-thaw semen quality, conception rate and preserved the integrity of the fine structure and the mitochondrial arrangement of the spermatozoa at a dose dependent manner. The high concentrations of melatonin inhibited the quality of sperm motility. These data are in accordance with results of (Fujinoki, 2008, Du Plessis et al., 2010 and 
Succu et al., 2011), who reported that the addition of melatonin to the semen freezing extender protected spermatozoa during cryopreservation and had beneficial effects on the post-thaw semen motility, viability and membrane integrity and significantly decreased the rate of lipid peroxidation of the cryopresreved spermatozoa in a dose-dependent manner.

However, the exact mechanism of sperm protection by melatonin has not been fully discovered and remains unclear. Variety of hypotheses and peculations has been proposed by various authors to explain the protective mechanism of melatonin. The current results may provide a novel mechanism of melatonin on the cryopresreved buffalo spermatozoa quality and fertilizing potentials. The positive effect of melatonin might be built on its ability to preserve the integrity of plasma membrane fine structure and mitochondrial arrangement of the spermatozoa, creating it less vulnerable to cryo-damage.

The results of the current study may be indicated by the results of (Tan et al., 2002, Du Plessis et al., 2010 and Espino et al., 2011) who found that melatonin might be due to potent scavenging effect of melatonin for reactive oxygen species (ROS). It had been established that ROS are highly reactive with complex cellular molecules such as proteins, lipids and DNA resulting in damaging of the cell membranes, triggering of apoptosis in spermatozoa, oocytes and embryos (Tatemoto et al., 2004 and Agarwal et al., 2006), inducing DNA fragmentation (Guérin et al., 2001), serious dysfunction of many enzymes (Halliwell and Gutteridge, 1989), mitochondrial abnormality and dysfunction (Lopes et al., 1998), damaging of RNA and protein synthesis (Comporti, 1989); which were generally thought to be harmful for embryonic development (Guérin et al., 2001). Therefore, melatonin is effective in lowering molecular damage under conditions of elevated oxidative stress due to potent scavenging effect of melatonin for ROS (Reiter et al., 2005).

Additionally, the beneficial action of melatonin on the cryopresreved buffalo spermatozoa and its fertilizing potentials may be due to preserve the mitochondrial dense structure and arrangement of the spermatozoa. Therefore, it would ultimately enhance the fertilizing potentials of the cryopresreved spermatozoa. Moreover, Martin et al. (2000) found that intra mitochondrial melatonin levels 100-fold higher than those of plasma indicating that melatonin had a potent physiological role in mitochondrial homeostasis (Martin et al., 2000). It had been reported that healthy condition of mitochondria was important for ATP production (Mtango et al., 2008), and regulation of cell survival (Dumollard et al., 2007). Whereas, aged mitochondria displayed decreased membrane potential and increased fragility (Dirks et al., 2006).
Furthermore, melatonin acts as an anti-apoptotic hormone through down-regulation of mitochondrial cytochrome $\mathrm{C}$ release and inhibition of activation of casp-9 and casp-3 (Molpeceres et al., 2007).

Therefore, results emerged from this study clearly demonstrated that supplementation of semen extender with melatonin exerted valuable effects on the quality and the fertilizing potentials of the cryopresreved buffalo spermatozoa. These constructive effects appeared due to its role in preserving the integrity of the plasma membrane fine structures, the mitochondrial dense structure and activity of the cryopresreved spermatozoa.

\section{REFERENCES}

Aboagla, E.M.E. and Terada, T. (2003): Trehalose enhanced fluidity of the goat sperm membrane and its protection during freezing. Biol. Reprod., 69: 1245-1250.

Adriaens, A.B.; Jacquet, P.B.; Cortvrindt, R.C.; Janssen, K.D. and Smitz, J. (2006): Melatonin has dose-dependent effects on folliculogenesis, oocyte maturation capacity and steroidogenesis. Toxicology, 228 (2-3): 333-343.

Agarwal, A.; Gupta, S. and Sikka, S. (2006): The role of free radicals and antioxidants in reproduction. Curr Opin Obstet. Gynecol., 18: 325-332.

Ashrafil, I.; Kohram, H.; Naijian, H.; Bahreini, M. and Poorhamdollah, M. (2001): Protective effect of melatonin on sperm motility parameters on liquid storage of ram semen at $5^{\circ} \mathrm{C}$. African J. Biotechnology 10 (34): 6670-6674.

Baydas, G.; Reiter, R.J.; Akbulut, M.; Tuzcu, M. and Tamer, S. (2005): Melatonin inhibits neural apoptosis induced by homocysteine in hippocampus of rats via inhibition of cytochrome $\mathrm{C}$ translocation and caspase-3 activation and by regulating pro- and antiapoptotic protein levels. Neuroscience, 135 (3): 879-886.

Berlinguer, F.; Leoni, G.G.; Succu, S.; Spezzigu, A.; Madeddu, M.; Satta, V.; Bebbere, D.; Contreras-Solis, I.; Gonzalez-Bulnes, A. and Naitana, S. (2009): Exogenous melatonin positively influences follicular dynamics, oocyte developmental competence and blastocyst output in a goat model. J. Pineal Res., 46(4): 383-391.

Boonkusol, D.; Saikhun, K. and Ratanaphumma, P. (2010): Effect of extender and storage time on motility and ultrastructure of cooled-preserved boar spermatozoa. Kasetsart J. Nat. Sci., 44: 582-589.

Bornman, M.S.; Oosthuizen, J.M.C.; Barnard, H.C.; Schulenburg, G.W.; Boomker, D. and Reif, S. 
(1989): Melatonin and sperm motility. Andrologia, 21: 483-485.

Bucak, M.N.; Tuncer, P.B.; Sariözkan, S. and Ulutas, P.A. (2009): Comparison of the effects of glutamine and an amino acid solution on postthawed ram sperm parameters, lipid peroxidation and anti-oxidant activities. Small Ruminant Res., 81: 13-17.

Casao, A.; Mendoza, N.; Pérez-Pé, R.; Grasa, A.; Abecia, J.A.; Forcada, F.; Cebrián-Peréz, J.A. and Muino-Blanco, T. (2010): Melatonin prevents capacitating and apoptotic-like changes of ram spermatozoa and increases fertility rate. J. Pineal Res., 48: 39-46.

Comporti, M. (1989): Three models of free radical induced cell injury. Chem. Biol. Interact, 72(12): $1-56$.

Correa, J.R. and Zavos, P.M. (1994): The hypoosmotic swelling test: its employment as an assay to evaluate the functional integrity of the frozen-thawed bovine sperm membrane. Theriogenology, 42: 351-360.

Costat Computer Program Copyright (1986): Version 3.03 copyright Cottort Software.

Dirks, A.J., Hofer, T.; Marzetti E.; Pahor, M. and Leeuwenburgh, C. (2006): Mitochondrial DNA mutations, energy metabolism and apoptosis in aging muscle. Ageing Res. Rev., 5: 179-195.

Dumollard, R.; Duchen, M. and Carroll, J. (2007): The role of mitochondrial function in the oocyte and embryo. Curr Top Dev. Biol., 77: 21-49.

Du Plessis, S.S.; Hagenaar, K. and Lampiao, F. (2010): The in vitro effects of melatonin on human sperm function and its scavenging activities on NO and ROS. Andrologia, 42 (2): 112-116.

Espino, J.; Ortiz, Á.; Bejarano, I.; Lozano, G.M.; Monllor, F.; García, J.F.; Rodríguez, A.B. and Pariente, J.A. (2011): Melatonin protects human spermatozoa from apoptosis via melatonin receptor-and extracellular signalregulated kinase-mediated pathways. Fertil. Steril., 95 (7): 2290-2296.

Fujinoki, M. (2008): Melatonin-enhanced hyperactivation of hamster sperm. Reprod., 136: 533-541.

Guérin, P.; El Mouatassim, S. and Ménézo, Y. (2001): Oxidative stress and protection against reactive oxygen species in the preimplantation embryo and its surroundings. Hum. Reprod. Update, 7(2): 175-189.

Halliwell, B. and Gutteridge, J. (1989): The chemistry of oxygen radicals and other derived species. In: Halliwell B and Gutteridge JMC, editor. Free radicals in biology and medicine. 2nd Ed. Oxford: Clerendon press, pp. 22-85.

Kang, J.T.; Koo, O.J.; Kwon, D.K.; Park, H.J.; Jang, G.; Kang, S.K. and Lee, B.C. (2009): Effects of melatonin on in vitro maturation of porcine oocyte and expression of melatonin receptor RNA in cumulus and granulosa cells. J. Pineal Res., 46 (1): 22-28.

Leboeuf, B.; Restall, B. and Salamon, S. (2000): Production and storage of goat semen for artificial insemination. Anim. Reprod. Sci., 62: 113-141.

Lenzi, A.; Gandini, L.; Lombardo, F.; Picardo, M.; Maresca, V. and Panfili, E. (2002): Polyunsaturated fatty acids of germ cell membranes, glutathione and glutathionedependent enzyme-PHGPx: from basic to clinic. Contraception, 65: 301-304.

Lopes, S.; Jurisicova, A.; Sun, J.G. and Casper, R.F. (1998): Reactive oxygen species: potential cause for DNA fragmentation in human spermatozoa. Hum. Reprod., 13(4): 896-900.

Martin, M.; Macias, M.; Escames, G.; Leon, J. and Acuña-Castroviejo, D. (2000): Melatonin but not vitamins $\mathrm{C}$ and $\mathrm{E}$ maintain glutathione homeostasis in t-butyl hydroperoxide-induced mitochondrial oxidative stress. FASEB, J., 14: 1677-1679.

Medeiros, C.M.O.; Forell, F.; Oliveira, A.T.D. and Rodrigues, J.L. (2002): Current status of sperm cryopreservation: why isn't it better? Theriogenology, 57: 327-344.

Mohammed, K.M.; Ziada, M.S. and Darwish, G.M. (1998): Practical trials for freezing semen of buffalo and Friesian bulls: Effect of various regimens of freezing, different milk extenders and types of straws packages on post-thawing semen characters. Assiut Vet. Med. J., 39 (77): 70-93.

Molpeceres, V.; Mauriz, J.L.; García-Mediavilla, M.V.; González, P.; Barrio, J.P. and González-Gallego, J. (2007): Melatonin is able to reduce the apoptotic liver changes induced by aging via inhibition of the intrinsic pathway of apoptosis. J. Biol. Med. Sci., 62(7): 687-695.

Mtango, N.R.; Harvey, A.J.; Latham, K.E. and Brenner, C.A. (2008): Molecular control of mitochondrial function in developing rhesus monkey oocytes and preimplantation-stage embryos. Reprod. Fertil. Dev., 20 (7): 846-859.

Revell, S.G. and Mrode, R.A. (1994): An osmotic resistance test for bovine semen. Anim. Reprod. Sci., 36: 77-86.

Reiter, R.J. (1991): The pineal gland: reproductive interactions. In: Pang PKT and Schreibman MP, editors. Vertebrate Endocrinology: Fundamental and biomedical implications. Vol. 4. Academic Press, San Diego, pp. 269310 (Part B).

Reiter, R.J.; Tan, D.X. and Maldonado, M.D. (2005): Melatonin as an antioxidant: physiology 
versus pharmacology. J. Pineal Res., 39(2): 215-216.

Succu, S.; Berlinguer, F.; Pasciu, V.; Satta, V.; Leoni, G.G. and Naitana, S. (2011): Melatonin protects ram spermatozoa from cryopreservation injuries in a dose-dependent manner. J. Pineal Res., 50, (3): 310-318.

Tan, D.X.; Reiter, R.J.; Manchester, L.C.; Yan, M.T.; El-Sawi, M.; Sainz, R.M.; Mayo, J.C.; Kohen, R.; Allegra, M. and Hardeland, R. (2002): Chemical and physical properties and potential mechanisms: Melatonin as a broad-spectrum antioxidant and free radical scavenger. Curr Topics Med. Chem., 2: 181-198.

Tatemoto, H.; Muto, N.; Sunagawa, I.; Shinjo, A. and Nakada, T. (2004): Protection of porcine oocytes against cell damage caused by oxidative stress during in vitro maturation: role of superoxide dismutase activity in porcine follicular fluid. Biol. Reprod., 71(4):1150-1157.

Watson, P.F. (2000): The causes of reduced fertility with preserved semen. Anim. Reprod. Sci., 60: 481-492.

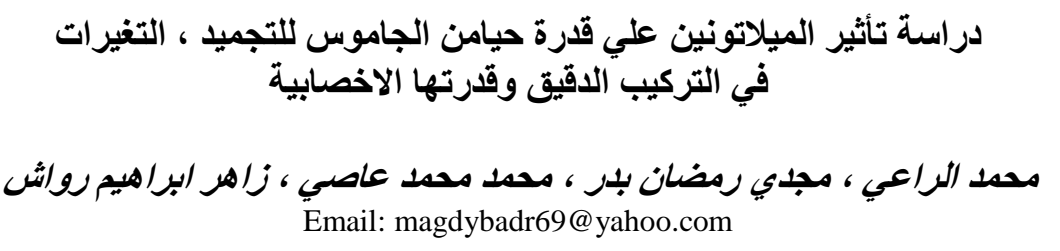

أجري هذا البحث لدر اسة تأثثر اضافة الميلاتونين الي ممدد السائل المنوى علي قابلية حيامن الجاموس للتجميد وكذا قدرتها الاخصـابية

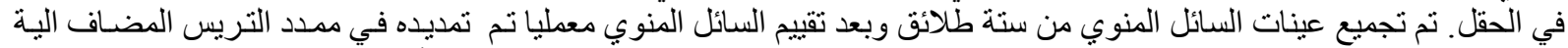

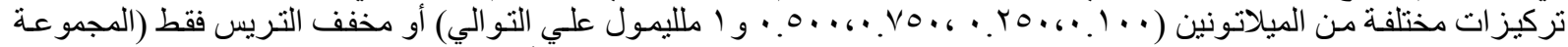

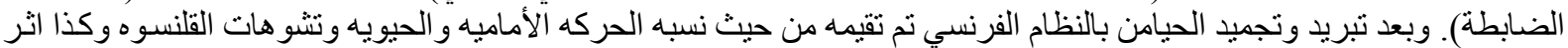

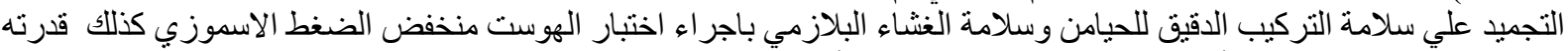

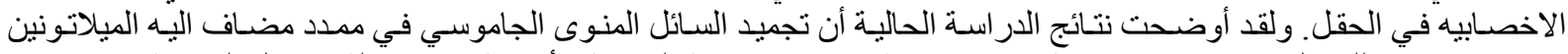

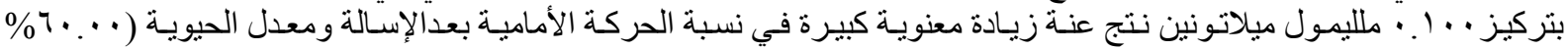

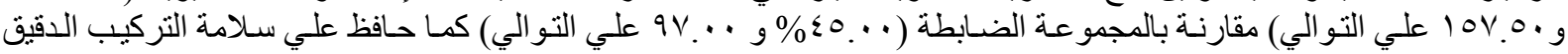

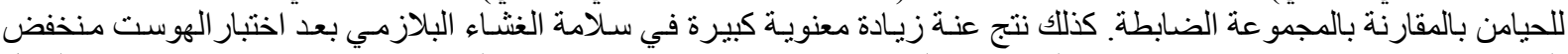

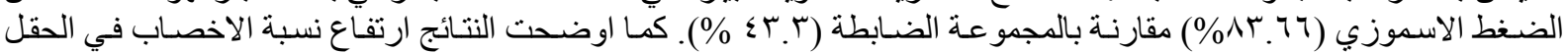

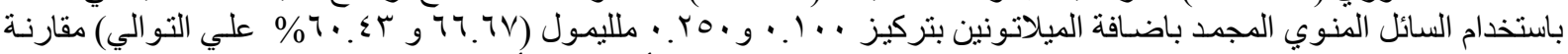

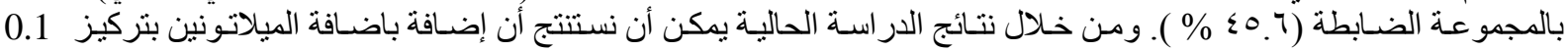

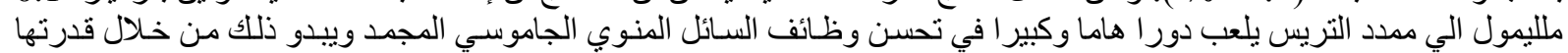
علي المحافظة علي سلامة التر اكيب الدقيقة للحيامن وزيادة نسبة الاخصاب في في الحقل. 